\title{
Dynamic Modeling of Multimode Resonance Measuring Mode in Atomic-Force Microscopy with Piezoresistive, Self-Actuating Cantilevers
}

\author{
Pavel S. Marinushkin*a, Alexey A. Levitskiy ${ }^{a}$, \\ Tzvetan Ivanov $^{\mathbf{b}}$ and Ivo W. Rangelow ${ }^{b}$ \\ ${ }^{a}$ Siberian Federal University \\ 79 Svobodny, Krasnoyarsk, 660041, Russia \\ ${ }^{b}$ Technische Universität Ilmena \\ Institut für Mikro- und Nanoelektronik \\ 1 Gustav-Kirchhoff Str., Ilmenau, 98693, Germany
}

Received 14.06.2018, received in revised form 19.06.2018, accepted 19.07.2018

The development of fast, qualitative and quantitative material characterization methods is one of the most important current issues in the field of nanosystems metrology. On this evidence it seems to be important to conduct a research on the capabilities of multimode resonance imaging mode in atomic-force microscopy (AFM) that allows broadening AFM capabilities in quality of nanonscale structures metrology and nano-object image quantitative analysis. The subject of this paper is modeling of physical phenomena that arise during the creation of such systems that describes coherent mechanic and electric phenomena in self-sensing and self-actuating cantilevers operating in multi-frequency resonance mode. The outcome of the research is represented by a virtual dynamic AFM model that allows understanding the signal generation process in AFM control and measuring circuits during sample scanning in multi-frequency mode.

Keywords: Atomic Force Microscope (AFM), Nano- and Microelectromechanical Systems (NEMS/ MEMS), nanometrology, self-actuating and self-sensing cantilever, thermomechanical actuation.

Citation: Marinushkin P.S., Levitskiy A.A., Ivanov T., Rangelow I.W. Dynamic modeling of multimode resonance measuring mode in atomic-force microscopy with piezoresistive, self-actuating cantilevers, J. Sib. Fed. Univ. Eng. technol., 2018, 11(6), 645-658. DOI: 10.17516/1999-494X-0082.

(C) Siberian Federal University. All rights reserved

This work is licensed under a Creative Commons Attribution-NonCommercial 4.0 International License (CC BY-NC 4.0)

* Corresponding author E-mail address: marinushkin_ps@mail.ru 


\title{
Динамическое моделирование многомодового \\ резонансного режима измерений
}

в атомно-силовой микроскопии

с пьезорезистивными активными кантилеверами

\author{
П.С. Маринушкин ${ }^{\mathrm{a}}$, А.А. Левицкий \\ Т. Иванов ${ }^{\tilde{0}}$, И.В. Рангелов ${ }^{\tilde{\sigma}}$ \\ ${ }^{a}$ Сибирский федеральный университет \\ Россия, 660041, Красноярск, пр. Свободныий, 79 \\ ${ }^{6}$ Технический университет Ильменау \\ Институт микро- и наноэлектроники \\ Германия, 98693, Ильменау, Густав Кирхгоф штрассе, 1
}

Проблема разработки высокоскоростных методов качественной и количественной характеризации материалов является одной из важнейших задач метрологии наносистем. $B$ связи с этим представляет интерес исследование возможностей многомодового резонансного режима атомно-силовой микроскопии (ACM), позволяющего расширить возможности АСМ в направлении повышения качества и достоверности количественного анализа изображений наноразмерных структур и нанообъектов. Предметом данной работы является рассмотрение вопросов создания динамической модели, описывающей взаимосвязанные механические и электрические процессы в саморегистрирующих активных кантилеверах, функционирующих в многочастотном резонансном режиме. Итогом работы является компьютерная динамическая модель АСМ, позволяющая исследовать процессы формирования сигналов, в управляющем и измерительных контурах АСМ при сканировании образиов в многочастотном режиме.

Ключевые слова: атомно-силовой микроскоп (АСМ), нано- и микроэлектромеханические системы (НЭМС/МЭМС), нанометрология, саморегистрирующий активный кантилевер, термомеханический привод.

\section{Introduction}

Since the AFM development thirty years ago [1-3], it became wide known as a high-performance tool for surface topography investigation of wide range of samples. Nevertheless the search for the optimum methods, which would describe samples properties and structure in the most complete way, drives the further development of AFM's. Methods for better surface visualization (sensitivity and resolution), scanning speed, and an ability to provide quantitative analysis of nano-mechanical properties and expanding the AFM applicability fields.

The most widely used method now is amplitude modulation method where cantilever resonant oscillations are generated at one of its own frequencies (e.g. at the first resonant frequency), while surface visualization is operated at a signal stipulated by oscillations amplitude attenuation as a result of interaction between a sample and a cantilever tip [4]. Nowadays the multimode mode is one of the most prospective ways to broaden the operating modes range, which opens new opportunities for AFM application [5-8].

The wide used method to measure the deflection of the cantilever customs a laser beam reflected from the surface of the cantilever onto a position-photodetector. When the cantilever is bended, the 
reflected laser light arise the cantilever at a different angle and provides in a measurable vertical shift of the laser spot on the detector. This method is called as beam detection.

The paper by Viani demonstrated the use of small cantilevers showing a high sensitivity and was used to unfold single molecules using imaging speeds an order of magnitude faster than previously performed with conventional cantilevers [9]. However, the use of small cantilever remains a challenging task using classical optical read-out techniques.

At the same time, during the surface scanning process tip deflection signal is also detected at excitation frequency. The drawback of this approach is the loss of additional useful information about sample that is contained in the deflection signal at frequencies that differ from excitation frequencies. This problem is overcome in the AFM multimode mode that implies cantilever oscillations generation andlor response measurement at one or more frequencies. The received additional information, i.e. amplitude, phase andlor frequency response, may be used for both surface visualization with high resolution [10-12] and simultaneously extraction of additional information about the sample's nanomechanical properties simultaneously [13, 14].

At the same time, the implementation of AFM multimode methods requires further theoretical discussion, as long as force interaction between the cantilever tip and the sample's surface in multimode mode is complex. As a result, experimental capabilities of AFM multimode mode now requires its theoretical understanding. In particular, the phase images, obtained with this mode, show clearly the detailed structure of the sample, however their physical interpretation is still unclear which obstructs a quantitative analysis of sample properties. Therefore, there is an actual need of research of measured response interpretation features in AFM multimode mode with considering its features and development of model-algorithmic support for near-surface structure properties measurement of materials and thin film in the micro- and nano-range.

\section{The features of AFM multimode mode hardware implementation}

The main measuring ingredient of atomic-force microscope is cantilever - a tiny force sensor in a form of cantilevered beam, the free end of which has a tip with sharpness at nano-range on it (Fig. 1).

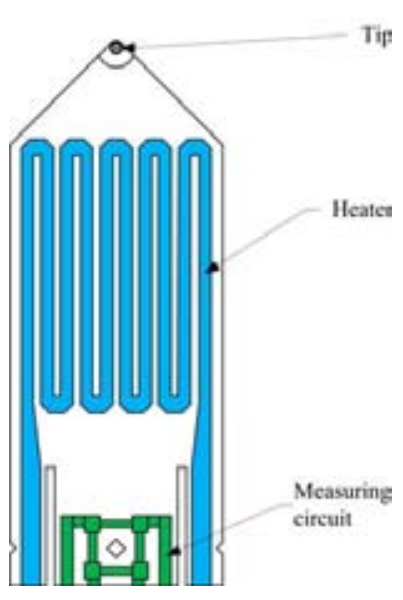

$a$

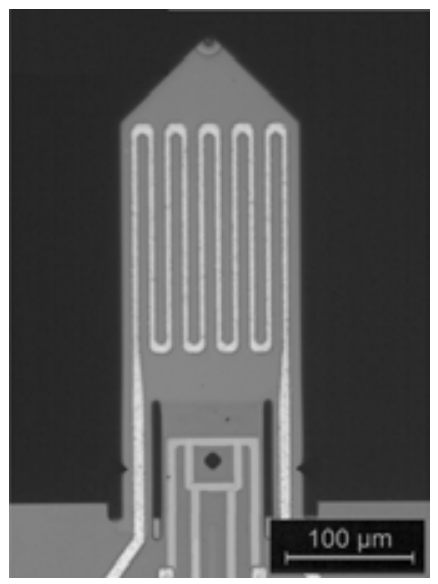

$b$

Fig. 1. Piezoresistive self-actuated cantilever: $a$ - cantilever scheme; $b$ - SEM picture

$$
-647-
$$


The self-sensing and self-actuating cantilever allows for much easier system integration and significant reduction in its weight. Hence, the microscope provides better controllability for full metrological automation and significant higher scan speeds.

The fabrication and basic characteristics of thermo-mechanically driven cantilevers with integrated resistive readout have been described in detail previously [15-17]. In brief: we use Si cantilevers $300 \mu \mathrm{m}$ long, $110 \mu \mathrm{m}$ wide, and 3-4 $\mu \mathrm{m}$ thick. The cantilevers have a piezoresistive Wheatstone-bridge positioned on the base of the cantilever and thermomechanical actuator located at near of the tip.

Probe tip vertical displacement is operated by thermomechanical actuator in form as a resistive heater on cantilever surface. The bridge measuring circuit, located on cantilever surface as well, is used for measuring the displacement.

The capability to record additional responses in amplitude, phase andlor oscillation frequencies is stipulated by complementing a widely used AFM single-frequency circuit by additional generators and synchronous detectors. The described above structural scheme is shown in Fig. 2.

In the presented scheme oscillation generators are used to excite several (in this case, the first three bending) oscillation forms of cantilever by an embedded thermomechanical actuator. A piezoscanner provides cantilever's displacement relative to the sample along $X, Y$ and $Z$ axis. As the cantilever tip approaches to the sample's surface, the force interaction arises between them, which lead

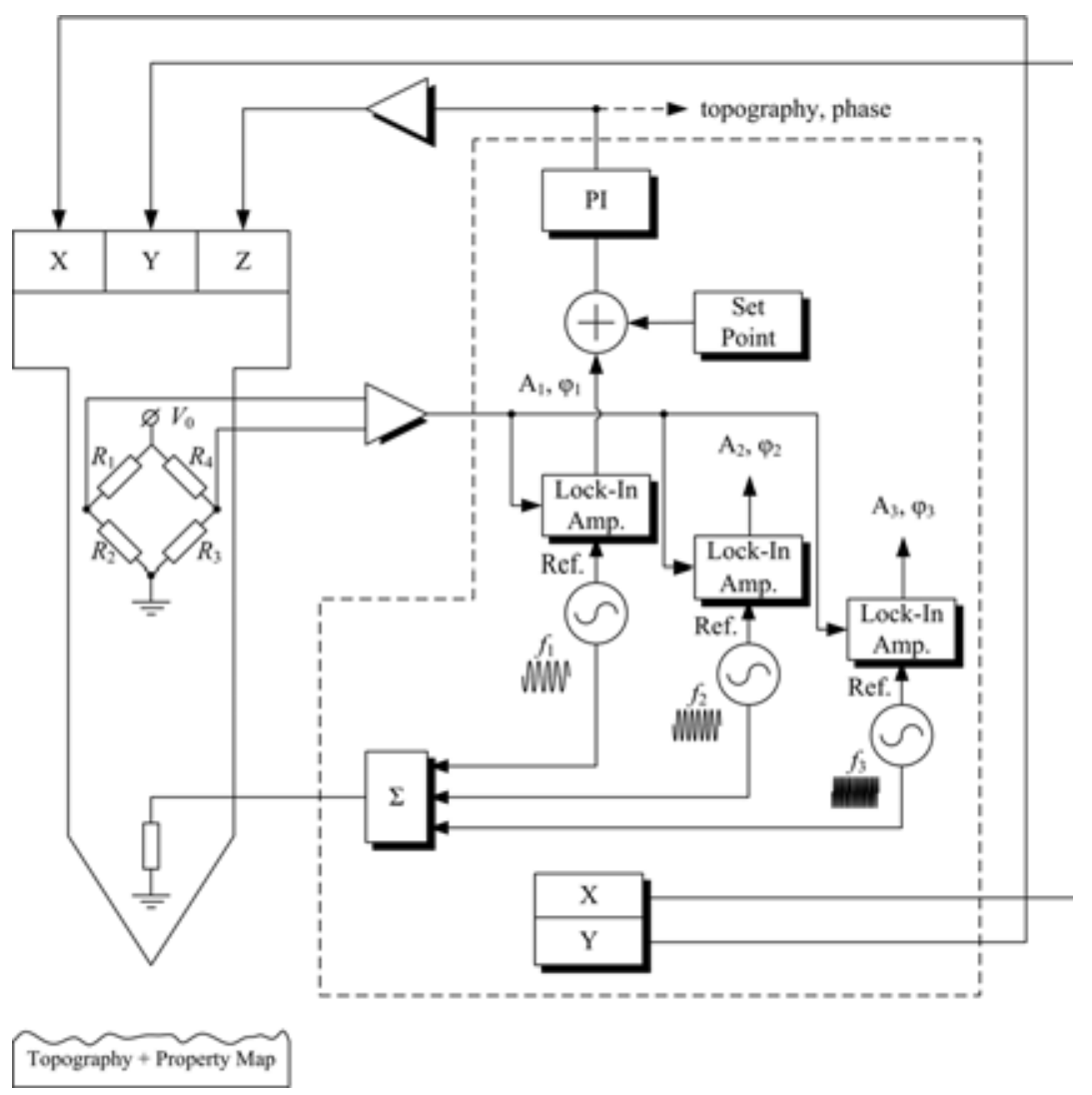

Fig. 2. The structural scheme of a multimode AFM. Here $f_{i}(i=1,2,3)$ are excitation frequencies; $A_{i}, \varphi_{i}$ are cantilever oscillation amplitudes measured at excitation frequencies $f_{i}$ 
to cantilever amplitude attenuation. When the surface profile of the sample changes, the force acting on the probe become different as well. Thus, there is amplitude modulation of cantilever oscillations by force acting on the probe from the surface. The cantilever mechanical response arising at this point is recorded. After that the acquired signal is amplified and sent to synchronous detectors inputs, reference signals of which are generator output voltages. This is the way to distinguish the envelopes of acquired signals. Then synchronous detectors output voltages are sent to the controller, after that they may be used for feedback while scanning the surface and may be displayed and recorded. Thus, regardless of the main information (topographic) channel cantilever oscillations may be controlled at higher natural frequencies, which allow researching a wider range of tip-sample interactions. Due to this, while scanning there is an opportunity to create a distribution map of other sample surface local properties, apart from topographic ones. The feedback is realized by complementing the scheme with a proportional-integrating link that forms a control signal further amplified and sent to $Z$-electrode of the scanner. At the output proportional-integrating link the signal is proportional to the sample surface topography height change. Based on this, the image of sample surface characteristics is further formed.

The opportunity of retrieving useful information from the additional data involves the necessity of researching mechanisms of informative signals conditioning during the sample surface scanning as well as it involves the development of reliable and exact amplitude, phase and frequency response interpretations. One of the most efficient solutions for this type of problem is simulation modeling. Unlike other methods, e.g. analytic, simulation modelling is able to describe functioning of the system almost without limitations in terms of detailing. Matlab Simulink has been used for implementation of AFM multi-frequency resonance mode simulation model as it was the most appropriate solution in this case.

The further questions of creating a mathematical description for multi-frequency AFM converters and electronic components in the framework of solving the problem of its simulation model creation will be carried by the example of AFM with active cantilever produced by the Nanoanalytik GmbH Company [18].

\section{Cantilever dynamic model}

The simplest model describing cantilever displacement (while scanning is one-dimensional model) considers cantilever as a resonator with lumped parameters. In case of multi-frequency cantilever excitation this model results in a system of $n$ differential equations, as follows:

$$
\begin{aligned}
& \frac{d^{2} z_{1}(t)}{d t^{2}}+\frac{c_{1}}{m_{1}} \frac{d z_{1}(t)}{d t}+\frac{k_{1}}{m_{1}} z_{1}(t)=\frac{F_{1}}{m_{1}} \sin \left(\omega_{1} t-\varphi_{1}\right)+\frac{F_{1}^{t s}}{m_{1}} \\
& \left.\frac{d^{2} z_{2}(t)}{d t^{2}}+\frac{c_{2}}{m_{2}} \frac{d z_{2}(t)}{d t}+\frac{k_{2}}{m_{2}} z_{2}(t)=\frac{F_{2}}{m_{2}} \sin \left(\omega_{2} t-\varphi_{2}\right)+\frac{F_{2}^{t s}}{m_{2}}\right\} \text {, } \\
& \frac{d^{2} z_{n}(t)}{d t^{2}}+\frac{c_{n}}{m_{n}} \frac{d z_{n}(t)}{d t}+\frac{k_{n}}{m_{n}} z_{n}(t)=\frac{F_{n}}{m_{n}} \sin \left(\omega_{n} t-\varphi_{n}\right)+\frac{F_{n}^{t s}}{m_{n}}
\end{aligned}
$$

where $z_{i}$ is the vertical cantilever tip displacement at the $i$-th oscillation mode; $m_{i}$ is the cantilever effective mass at the $i$-th oscillation mode; $k_{i}$ is the cantilever stiffness at the $i$-th oscillation mode;

$$
-649-
$$


$\omega_{i}$ is the natural frequency at the $i$-th oscillation mode $\left(\omega_{i}=\sqrt{k_{i} / m_{i}}\right) ; F_{i}$ is the amplitude of the $i$-th excitatory force; $\varphi_{i}$ is the initial phase of the $i$-th oscillation; $F_{i}^{t s}$ is the interaction strength between cantilever tip and the sample's surface at $i$-th oscillation mode; $c_{i}$ is the damping coefficient of $i$-th oscillation mode:

$$
c_{i}=2 m_{i} \omega_{i} \zeta_{i}=\frac{m_{i} \omega_{i}}{Q_{i}},
$$

where $\zeta_{i}$ is the relative damping coefficient; $Q_{i}$ is the quality coefficient of the $i$-th oscillation mode.

With the aim to transform model (1) to the form that would be more convenient for the structural modeling, it is considered rational to describe it as a state space. A dynamic object model in the state space is presented as an aggregate of physical variables $q_{1}(t), \ldots, q_{n}(t)$ that determine object's behavior in the further moments of time, on condition that the object's state at the first moment of time and all the applied impacts are known. The connection between input variables $u_{1}(t), \ldots, u_{n}(t)$, output variables $p_{1}(t), \ldots, p_{n}(t)$ and state variables $q_{1}(t), \ldots, q_{n}(t)$ is represented by the first-order differential equations written in matrix form.

The following variables are introduced as the mentioned above state parameters:

$$
\left.\begin{array}{rl}
q_{1}^{(1)}(t) & =p_{1}(t) \\
q_{1}^{(2)}(t) & =\frac{d p_{1}(t)}{d t} \equiv \frac{d q_{1}^{(1)}}{d t} \\
\cdots \\
q_{n}^{(1)}(t)=p_{n}(t) \\
q_{n}^{(2)}(t)=\frac{d p_{n}(t)}{d t} \equiv \frac{d q_{n}^{(1)}}{d t}
\end{array}\right\},
$$

Substituting (2) into (1) results in the following system of equations in state variables:

$$
\dot{\mathbf{q}}=\mathbf{A q}+\mathbf{B u}=\left[\begin{array}{lll}
\mathbf{A}_{1} & & 0 \\
& \ddots & \\
0 & & \mathbf{A}_{n}
\end{array}\right] \mathbf{q}+\left[\begin{array}{lll}
\mathbf{B}_{1} & & 0 \\
& \ddots & \\
0 & & \mathbf{B}_{n}
\end{array}\right] \mathbf{u},
$$

where $\mathbf{q}$ is the state vector, $\mathbf{u}$ is the vector of input effects, $\mathbf{A}(n \times n)$ is the system's state matrix, $\mathbf{B}(n \times r)$ is the control (input) matrix.

$$
\mathbf{q}=\left[\begin{array}{lllll}
q_{1}^{(1)} & q_{1}^{(2)} & \ldots & q_{n}^{(1)} & q_{n}^{(2)}
\end{array}\right]^{T}, \mathbf{A}_{i}=\left[\begin{array}{cc}
0 & 1 \\
-\frac{k_{i}}{m_{e f f}} & -\frac{c_{i}}{m_{e f f}}
\end{array}\right], \mathbf{B}_{i}=\left[\begin{array}{ll}
0 & 0 \\
1 & 1
\end{array}\right] .
$$

For complete description of dynamic model the state equation's dynamic model has to be complemented (3) with equations making up a connection between the state variables $q_{1}^{(1)}, q_{1}^{(2)}, \ldots, q_{n}^{(1)}, q_{n}^{(2)}$ and the output variables $p_{1}, \ldots, p_{n}$ :

$$
\mathbf{p}=\mathbf{C q}+\mathbf{D u},
$$

where $\mathbf{p}$ is the output vector, $\mathbf{C}(m \times n)$ is the output matrix, $\mathbf{D}(m \times r)$ is the output control matrix. 


$$
\mathbf{p}=\left[\begin{array}{c}
p_{1} \\
\vdots \\
p_{n}
\end{array}\right], \mathbf{C}=\left[\begin{array}{lll}
\mathbf{C}_{1} & & 0 \\
& \ddots & \\
0 & & \mathbf{C}_{n}
\end{array}\right], \mathbf{C}_{i}=\left[\begin{array}{ll}
1 & 0
\end{array}\right], \mathbf{D}=\left[\begin{array}{cccccc}
0 & 0 & 0 & 0 & 0 & 0 \\
0 & 0 & 0 & 0 & 0 & 0 \\
0 & 0 & 0 & 0 & 0 & 0
\end{array}\right]
$$

The cantilever frequency characteristics based on the resulting model in accordance with the Matlab Simulink parameters given in Table 1, are presented in Fig. 3.

Table 1. Cantilever dynamic model parameters

\begin{tabular}{|c|c|}
\hline Parameter & Value \\
\hline Effective mass $m_{1}, \mathrm{~kg}$ & $2.812 \cdot 10^{-10}$ \\
\hline Effective mass $m_{2}, \mathrm{~kg}$ & $8.072 \cdot 10^{-11}$ \\
\hline Effective mass $m_{3}, \mathrm{~kg}$ & $2.564 \cdot 10^{-11}$ \\
\hline Stiffness $k_{1}, \mathrm{~N} / \mathrm{m}$ & 53.644 \\
\hline Stiffness $k_{2}, \mathrm{~N} / \mathrm{m}$ & 652.913 \\
\hline Stiffness $k_{3}, \mathrm{~N} / \mathrm{m}$ & 1541.808 \\
\hline
\end{tabular}

\begin{tabular}{|c|c|}
\hline Parameter & Value \\
\hline Mechanical quality $Q_{1}$ & 134 \\
\hline Mechanical quality $Q_{2}$ & 253 \\
\hline Mechanical quality $Q_{3}$ & 286 \\
\hline Resonance frequency $f_{1}, \mathrm{~Hz}$ & 69509 \\
\hline Resonance frequency $f_{2}, \mathrm{~Hz}$ & $4.527 \cdot 10^{5}$ \\
\hline Resonance frequency $f_{3}, \mathrm{~Hz}$ & $1.235 \cdot 10^{6}$ \\
\hline
\end{tabular}

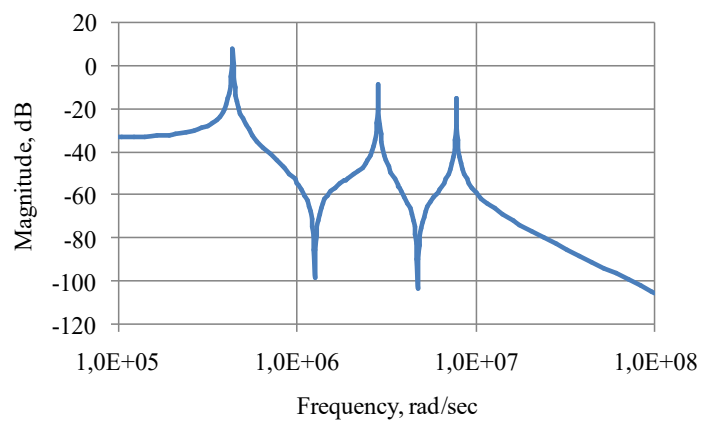

$a$

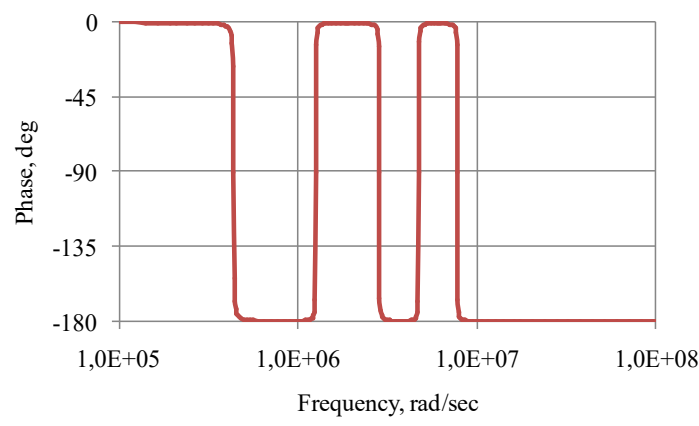

$b$

Fig. 3. Amplitude-frequency (a) and phase-frequency (b) cantilever characteristics

\section{Thermomechanical actuator model}

Thermomechanical actuator is by design a resistive heater on the cantilever surface of mass $m_{h}$ and specific heat $c_{h}$ that initially has resistance $R_{h 0}$ at ambient temperature $T_{0}$. When the electric current $i$ flows through the conductor with resistance $R_{h}$, the power is $P$. The temperature of the conductor rises by $\Delta T$. Power that allocates at conductor's resistance, depending on overheating temperatures (relatively to the initial ambient temperature), is determined by the following expression:

$$
P(t)=i^{2} R_{h 0}(1+\beta \Delta T(t)),
$$

where $\Delta T(t)=T(t)-T_{0}$ is the overheat relatively to the initial temperature, $\beta$ is the temperature coefficient of resistance.

Then the amount of heat accumulated in the conductor is: 


$$
Q_{h}(t)=\int_{0}^{t} \Delta P(t) d t
$$

The defining equation for thermomechanical actuator is the differential equation of heat balance:

$$
c_{h} m_{h} \frac{d T}{d t}=Q_{h}(t)-\alpha S\left(T-T_{c}\right)
$$

where $T$ is the heater temperature, $t$ is the time, $\alpha$ is the reduced heat transfer coefficient, $S$ is the surface area of the heater, $T_{c}$ is the ambient temperature.

Due to the difference between thermal expansion coefficients of cantilever materials $(\mathrm{Si}-$ the base, $\mathrm{Al}$ - metallization) the heat produced by the heater causes mechanical stresses in cantilever and, as a result, bending. The displacement $d$ of the tip along the axis $Z$ may be calculated by [19]:

$$
d=\frac{\rho L^{2}}{2}
$$

where $L$ is the cantilever length, $\rho$ is the curvature of the cantilever's bent axis [19]:

$$
k=\frac{1}{r}=\frac{6 b_{\mathrm{Si}} b_{\mathrm{Al}} E_{\mathrm{Si}} E_{\mathrm{Al}} t_{\mathrm{Si}} t_{\mathrm{Al}}\left(t_{\mathrm{Si}}+t_{\mathrm{Al}}\right)\left(\alpha_{\mathrm{Si}}-\alpha_{\mathrm{Al}}\right) \Delta T}{\left(b_{\mathrm{Si}} E_{\mathrm{Si}} t_{\mathrm{Si}}^{2}\right)^{2}+\left(b_{\mathrm{Al}} E_{\mathrm{Al}} t_{\mathrm{Al}}^{2}\right)^{2}+2 b_{\mathrm{Si}} b_{\mathrm{Al}} E_{\mathrm{Si}} E_{\mathrm{Al}} t_{\mathrm{Si}} t_{\mathrm{Al}}\left(2 t_{\mathrm{Si}}^{2}+3 t_{\mathrm{Si}} t_{\mathrm{Al}}+2 t_{\mathrm{Al}}^{2}\right)},
$$

where $r$ is the curvature radius, $b_{\mathrm{Si}}$ and $b_{\mathrm{Al}}$ are the width of silicon and aluminum layers, respectively; $\alpha_{\mathrm{Si}}$ и $\alpha_{\mathrm{Al}}$ are the coefficients of silicon and aluminum thermal expansion, respectively; $E_{\mathrm{Si}}$ и $E_{\mathrm{Al}}$ are the silicon and aluminum elasticity modulus.

Then equivalent force developed by the actuator is:

$$
F_{e q} \approx \frac{3 E I d}{L^{3}},
$$

where $I$ is the moment of section inertia, $E I$ is the equivalent rigidity defined by the following expression [20]:

$$
E I=\frac{E_{\mathrm{Si}} b_{\mathrm{Si}} t_{\mathrm{Al}}\left(t_{\mathrm{Si}}+t_{\mathrm{Al}}\right)^{2}}{2}
$$

\section{Model of power interaction between cantilever tip and sample}

It is possible to study a sample only due to the variety of powers appearing between the cantilever tip and the sample while surface scanning. Depending on the probe-sample distance different forces may prevail.

For instance, in the attraction mode (tip moving away from the sample) the prevailing type of interaction is Van der Waals force of intermolecular interaction. In the repulsion mode (tip approaching to the sample) elastic and inelastic interactions with the sample prevail. The interactions are calculated from the Derjagin-Muller-Toropov model [21]:

$$
F_{t s}(h)= \begin{cases}-\frac{H R_{t i p}}{6 h^{2}} & \text { in attraction mode }\left(h>a_{0}\right) \\ -\frac{H R_{t i p}}{6 a_{0}^{2}}+\frac{4}{3} E^{*} \sqrt{R_{t i p}}\left(a_{0}-h\right)^{\frac{3}{2}} & \text { in repulsion mode }\end{cases}
$$


where $H$ is the Hamaker constant, $R_{t i p}$ is the radius of cantilever tip curvature, $h=z_{\mathrm{s}}+\Delta z$ is the distance between the cantilever tip and the sample surface ( $\Delta z$ is the cantilever deflection value, $z_{\mathrm{s}}$ is the distance between the un-bended cantilever and the sample), $a_{0}$ is the intermolecular (interatomic) distance, $E^{*}$ is the effective modulus of elasticity of the probe-sample system:

$$
\frac{1}{E^{*}}=\frac{\left(1-v_{t}\right)^{2}}{E_{t}}+\frac{\left(1-v_{s}\right)^{2}}{E_{s}},
$$

where $E_{t}$ and $E_{s}$ are the modulus of tip and sample materials elasticity, respectively, $v_{\mathrm{t}}$ and $v_{\mathrm{s}}$ are Poisson's ratios of the tip and the sample materials, respectively.

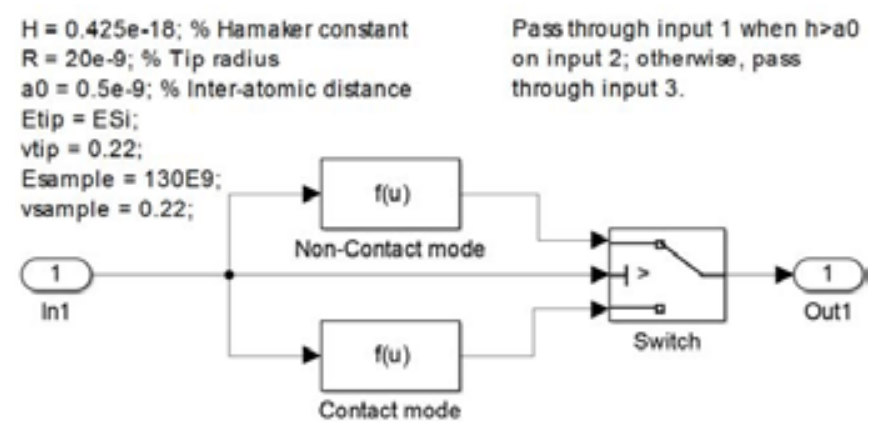

Fig. 4. Structural model of the block modeling tip-sample interaction

\section{Measuring circuit model}

Responses that come up during the scanning of the sample are recorded by a measuring circuit, embedded into the cantilever. The cantilever measuring circuit in the Nanoanalytik $\mathrm{GmbH}$ company's atomic-force microscope is formed by the system of four piezoresistors $\left(R_{1}\right.$, $R_{3}$ from one side and $R_{2}, R_{4}$ from the other) with the resistance of $1098 \mathrm{ohms}$ each one. All of the piezoresistors are located so that cantilever deformation causes resistance changes, equal in absolute value and opposite in sign, in the adjacent shoulders of the bridge. The typical reference voltage is $V_{0}=2.5 \mathrm{~V}$.

At the output of the measuring circuit the measured voltage $V_{\text {out }}$ is proportional to the difference of the relative resistances:

$$
V_{\text {out }}=V_{0}\left(\frac{R_{2}}{R_{1}+R_{2}}-\frac{R_{3}}{R_{3}+R_{4}}\right),
$$

where $V_{0}$ is the reference voltage applied to the measuring circuit.

While scanning, the cantilever perceives the external force action $F$ from the surface, causing its deflection $\Delta z$ :

$$
F=k \Delta z
$$

where $k=\frac{3 E I}{L^{3}}$ is the cantilever stiffness. 
It is obvious that the maximum cantilever deflection is observed at the loose end $(Y=L$ coordinate):

$$
\Delta z(L)=\frac{L^{3}}{3 E I} F
$$

The maximum bending moment for the cantilever under research loaded at the end by the concentrated force $F$ appears at the attachment point $(Y=0)$ and is expressed by:

$$
M=F(L-Y) \Rightarrow M_{\max }=F L .
$$

Mechanical stresses from the given load reach the greatest value on its surface $Z= \pm t_{1} / 2$ in the section where $M_{\max }$ acts, i.e. in the place where the cantilever is clamped [22]:

$$
\left|\sigma_{\max }\right|=\frac{M_{\max } Z}{I}=\frac{F L b}{2 I}=\frac{3 E b}{2 L^{2}} z
$$

At last, mechanical stresses' impact on each of the piezoresistors included in the measuring circuit with the resistance $R_{i}$ causes the resistance increment $\Delta R_{i}$ :

$$
\Delta R=\pi \sigma_{\max } R_{0},
$$

where $\pi$ is the piezoresistive coefficient, the value and the sign of which depend on the resistor's location at the cantilever (the longitudinal piezoresistive coefficient is $\pi_{l}=70 \mathrm{e}-11 \mathrm{~Pa}^{-1}$, the transverse piezoresistive coefficient is $\pi_{t}=-\pi_{l}$ ).

The cantilever measuring circuit model created in conformity with the ratio described above is presented at Fig. 5 .

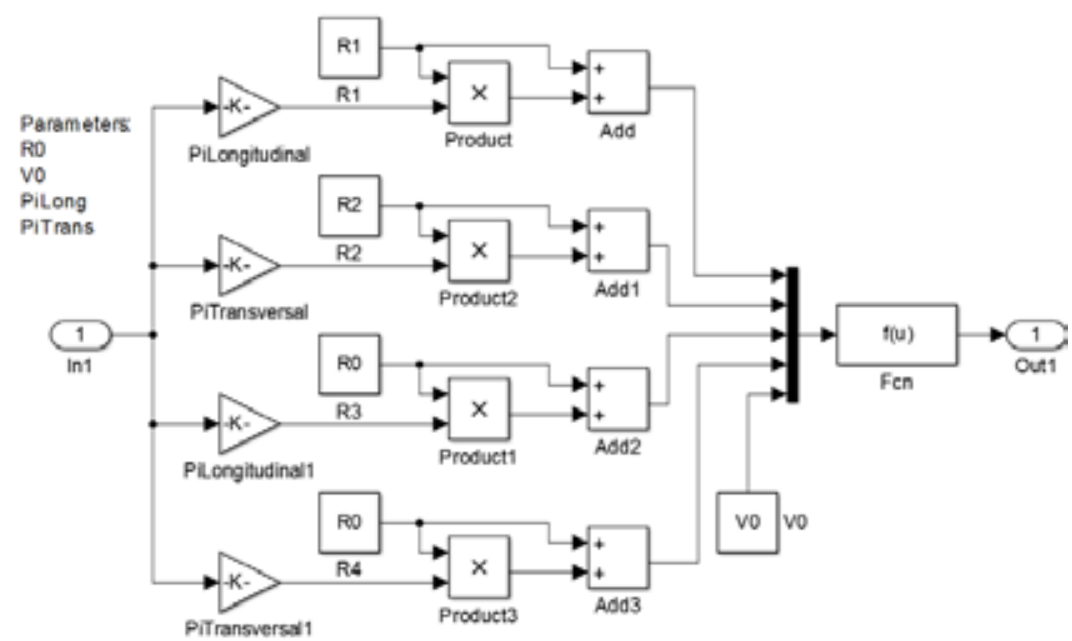

Fig. 5. The cantilever measuring circuit model

\section{Simulation model of atomic-force microscope}

The developed mathematical models of AFM converters and electronic assemblies, implemented as algorithmic blocks, allow switching to a multi-frequency AFM simulation model. The microscope 


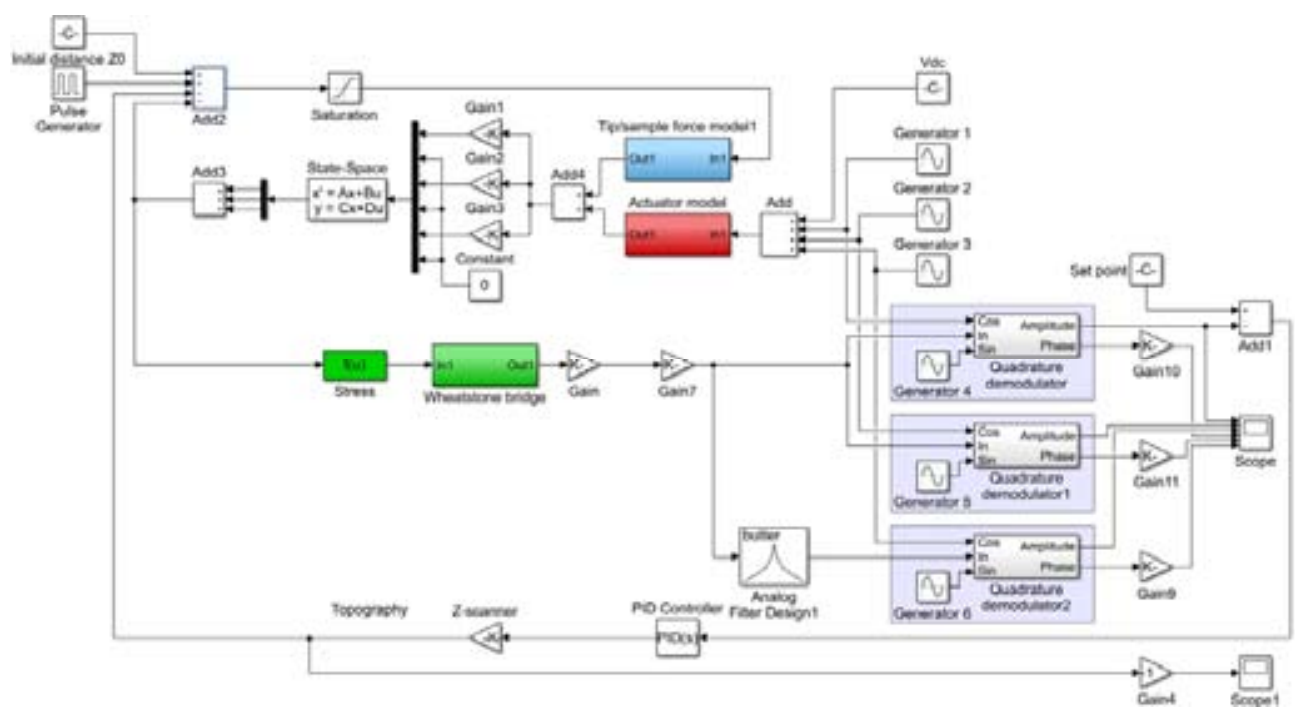

Fig. 6. The simulation model of the multi-frequency atomic-force microscope

model described by a differential equations system has been implemented by means of Matlab Simulink package as a structural scheme (Fig. 6).

As the basis for the model the parameters matching the Nanoanalytik Gmbh company's atomicforce microscope cantilever were taken: cantilever length $L=350 \mu \mathrm{m}$, cantilever width $w=140 \mu \mathrm{m}$, aluminum layer thickness $t_{\mathrm{Al}}=0.7 \mu \mathrm{m}$, silicon oxide layer thickness $t_{\mathrm{SiO} 2}=0.5 \mu \mathrm{m}$, silicon layer thickness $t_{\mathrm{Si}}=2 \mu \mathrm{m}$, silicon elasticity modulus $E_{\mathrm{Si}}=170 \mathrm{GPa}$, aluminum elasticity modulus $E_{\mathrm{Al}}=70 \mathrm{GPa}$, coefficient of aluminum linear expansion $\alpha_{\mathrm{Al}}=23.3 \cdot 10^{-6}{ }^{\circ} \mathrm{C}^{-1}$, coefficient of silicon linear expansion $\alpha_{\mathrm{Si}}=2.616 \cdot 10^{-6}{ }^{\circ} \mathrm{C}^{-1}$, temperature coefficient of aluminum resistance $\beta_{\mathrm{Al}}=4.3 \cdot 10^{-3}{ }^{\circ} \mathrm{C}^{-1}$, heat capacity $c_{\mathrm{Al}}=753 \mathrm{~J} /(\mathrm{kg} \cdot \mathrm{K})$, heat capacity $c_{\mathrm{Si}}=713 \mathrm{~J} /(\mathrm{kg} \cdot \mathrm{K})$, radius of cantilever tip $R_{\text {tip }}=20 \mathrm{~nm}$, Poisson's ratio of the tip material $v_{\text {tip }}=0.22$, thermomechanical actuator resistance $R_{h 0}=24 \mathrm{Ohm}$.

Examples of exciting impacts and measuring responses obtained by simulation modeling in Simulink are shown in Fig. 7.

Examples of measuring responses to the surface topography in the form of a periodic structure with a trapezoidal profile $50 \mathrm{~nm}$ high, received after simulation in the Simulink environment, are presented in Fig. 8. The envelope $A_{1}$ of the amplitude modulated signal at the first resonant frequency is used for feedback during the scanning of the surface. Second and the third modes of the cantilever provide two more channels of extra information $A_{2}, \phi_{2}$ and $A_{3}, \phi_{3}$. Values plotted on the graphs along the vertical axes can give an estimate of the magnitude of informative signals. Noticeable in Fig. 8, $c$ artifacts expressed in signals jumps can be attributed to insufficiently accurate setting of the feedback loop parameters. Overall, the results indicate that the model correctly reflects the nature of the relationships between the input impacts and the response signals and corresponds to theoretical concepts.

\section{Conclusion}

In this paper we have presented a model describing the operation of self-actuating and self- sensing cantilevers and their mechanical and electrical characteristics. This paper presents also particularly a 

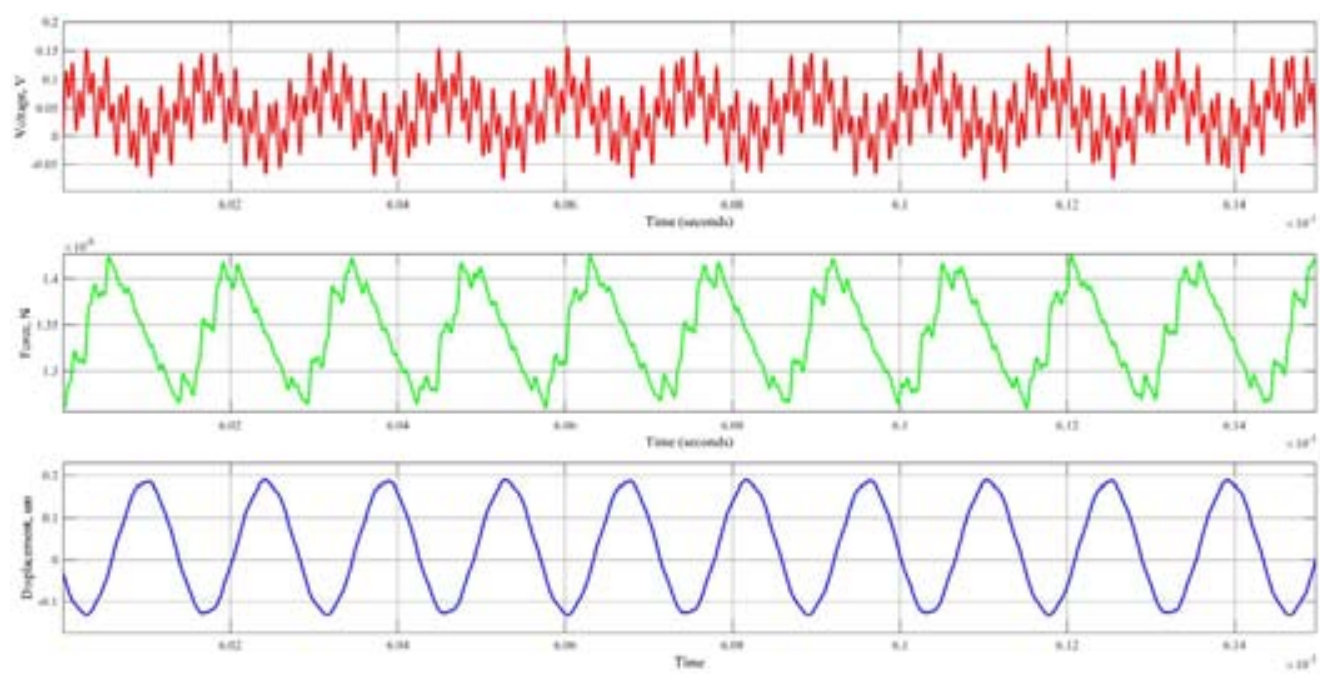

Fig. 7. Examples of modeling: $a$ - cantilever oscillation electric exciting signal (sum of signals with frequencies $\left.f_{1}, f_{2}, f_{3}\right) ; b$ - time dependence of the force developed by the thermomechanical actuator; $c$ - vertical displacement of cantilever tip

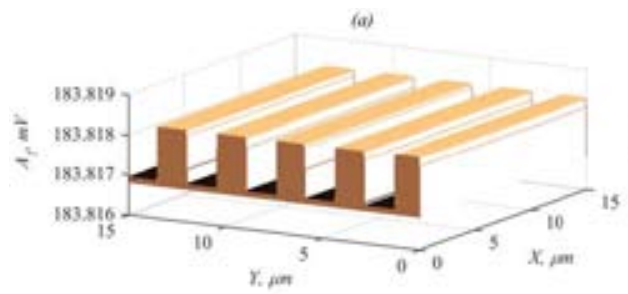

(c)

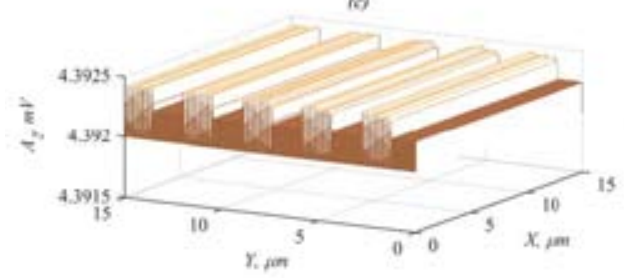

10

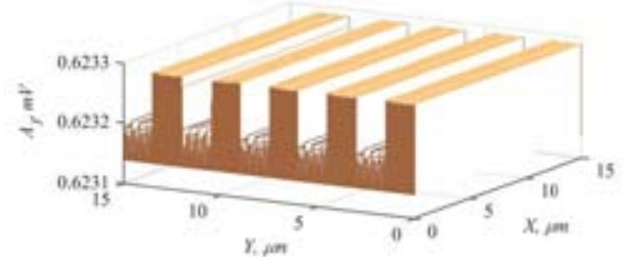

(b)

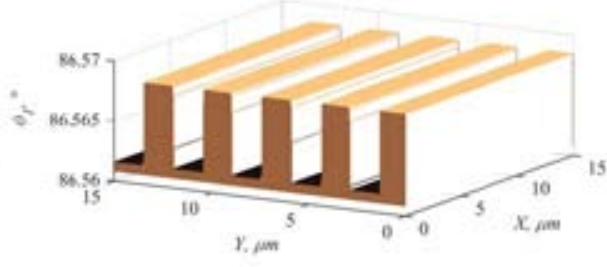

(d)

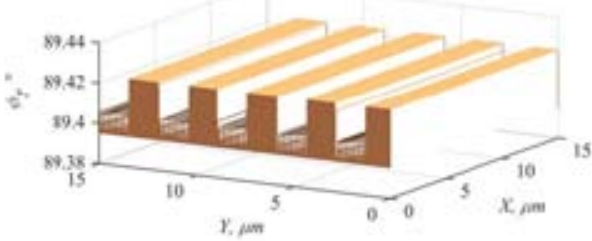

6

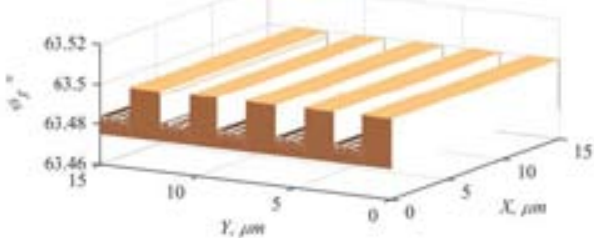

Fig. 8. Examples of simulation response results: $a, c, e$-amplitude responses of $A_{1}, A_{2}$ and $A_{3}$, respectively; $b, d$, $f$-phase responses $\phi_{1}, \phi_{2}$ and $\phi_{3}$, respectively. The size of field under research is $15 \times 15 \mu \mathrm{m}$

dynamical model of the multimode AFM that can be applied for modeling measuring responses of the multi-frequency atomic-force microscopy. The model considers the input parameters in the form of surface topography of an arbitrary profile, including the materials with heterogeneity of mechanical properties. 
The developed model allows researching and interpreting the measured responses in the multimode mode AFM taking into account its natural features. Also it is of interest as a basis for development of model-algorithmic support for measurements of the surface properties of materials and thin film structures in micro- and nanoscales using self-sensing and self-actuating cantilevers.

\section{Acknowledgments}

This work was supported by the German Academic Exchange Service (DAAD) and the Ministry of Education and Science of the Russian Federation under funding programme "Mikhail-LomonosovProgramme-Linie A, 2016”.

\section{References}

[1] Binnig G. Atomic force microscope and method for imaging surfaces with atomic resolution, U.S. Patent No. 4, 724, 318 (4 August 1986).

[2] Binnig G., Quate C. F., Gerber C. Atomic force microscope, Phys. Rev. Lett, 1986, 56, 930. doi: 10.1103/PhysRevLett.56.930

[3] Binnig G., Rohrer H., Gerber C., Weibel E. Tunneling through a controllable vacuum gap, Appl. Phys. Lett, 1982, 40, 178. doi: 10.1063/1.92999

[4] Bowen W. R., Hilal N. Atomic force microscopy in process engineering. An introduction to AFM for improved processes and products, Butterworth-Heinemann, 2009. $290 \mathrm{p}$.

[5] Rodriguez T., Garcia R. Compositional mapping of surfaces in atomic force microscopy by excitation of the second normal mode of the microcantilever, Appl. Phys. Lett, 2004, 84, 449-451.

[6] Proksch R. Multifrequency, repulsive-mode amplitude-modulated atomic force microscopy, Appl. Phys. Lett, 2006, 89, 113-121.

[7] Martinez N. F., Patil S., Lozano J. R., Garcia R. Enhanced compositional sensitivity in atomic force microscopy by the excitation of the first two flexural modes, Appl. Phys. Lett, 2006, 89, 153-115.

[8] Kawai S., Glatzel T., Koch S., Such B., Baratoff A., Meyer E. Systematic achievement of improved atomic-scale contrast via bimodal dynamic force microscopy, Phys. Rev. Lett, 2009, 103 (22): 220-801. doi: 10.1103/PhysRevLett.103.220801

[9] Viani M. B., Schaffer T. E., Chand A., Rief M., Gaub H. E., Hansma P. K. Small cantilevers for force spectroscopy of single molecules, J. Appl. Phys, 1999, 86, 22-58. doi: 10.1063/1.371039

[10] Ebeling D., Eslami B., Solares S. Visualizing the subsurface of soft matter: simultaneous topographical imaging, depth modulation, and compositional mapping with triple frequency atomic force microscopy, ACS Nano, 2013, 7, 10387-10396.

[11] Santos S. Enhanced sensitivity and contrast with bimodal atomic force microscopy with small and ultra-small amplitudes in ambient conditions, Appl. Phys. Lett, 2013, 103, 231-603. doi: 10.1063/1.4840075

[12] Damircheli M., Payam A., Garcia R. Optimization of phase contrast in bimodal amplitude modulation AFM, Beilstein J. Nanotechnol, 2015, 6, 1072-1081.

[13] Garcia R., Proksch R. Nanomechanical mapping of soft matter by bimodal force microscopy, European Polymer Journal, 2013, 49, 1897-1906.

[14] Herruzo E., Perrino A., Garcia R. Fast nanomechanical spectroscopy of soft matter, Nature Communications, 2014, 5. doi:10.1038/ncomms4126 
[15] Rangelow I. W., Skocki S., Dumania P. Plasma etching for micromechanical sensor applications, Microelectron. Eng, 1994, 23, 365-368.

[16] Linnemann R., Gotszalk T., Hadjiiski L., Rangelow I. W. Characterization of a Cantilever With an Integrated Deflection Sensor, Thin Solid Films, 1995, 264 (2), 159-164. doi: 10.1016/00406090(94)05829-6

[17] Pedrak R., Ivanov Tzv., Ivanova K., Gotszalk T., Abedinov N., Rangelow I. W. Micromachined atomic force microscopy sensor with integrated piezoresistive sensor and thermal bimorph actuator for high-speed tapping-mode atomic force microscopy phase-imaging in higher eigenmodes, J. Vac. Sci. Technol., 2003, B 21, 3102. doi: 10.1116/1.1614252

[18] Universal, active AFM Cantilever (AFM-CL) Piezoresistive probes with direct-driven actuation (RDD's). Access: http://www.nanoanalytik.net/afm-canti.html

[19] Chu W.-H., Mehregany M., Mullen R. L., Analysis of tip deflection and force of a bimetallic cantilever microactuator, Journal of Micromechanics and Microengineering, 1993, 3 (1). doi: 10.1088/0960-1317/3/1/002

[20] Gryzagoridis J., Oliver G., Findeis D. On the equivalent flexural rigidity of sandwich composite panels. Insight 2015, 57, 140-143.

[21] Derjaguin B. V., Muller V. M., Toropov Yu. P. Effect of contact deformations on the adhesion of particles, J. Colloid. Interface Sci, 1975, 53 (2), 314-326.

[22] Kaajakari V. Practical MEMS: Design of microsystems, accelerometers, gyroscopes, RF MEMS, optical MEMS, and microfluidic systems. Las Vegas: Small Gear Publishing, 2009. 484 p. 